(c) American Dairy Science Association, 2003.

\title{
Genetic Relationship Between Body Condition Score, Dairy Character, Mastitis, and Diseases Other than Mastitis in First-Parity Danish Holstein Cows
}

\author{
J. Lassen, ${ }^{\star} ¥$ M. Hansen, ${ }^{\star}$ M. K. Sørensen, ${ }^{\star}$ G. P. Aamand, $†$ \\ L. G. Christensen, $¥$ and P. Madsen* \\ *Department of Animal Breeding and Genetics, \\ Danish Institute of Agricultural Sciences, \\ Research Centre Foulum, P.O. Box 50 DK-8830 Tjele, Denmark \\ †The Danish Agricultural Advisory Centre, \\ Udkaersvej 15, Skejby, DK-8200 Aarhus N, Denmark \\ ‡Department of Animal Science and Animal Health, \\ The Royal Veterinary and Agricultural University, \\ Bülowsvej 13, DK-1870 Frederiksberg C, Denmark
}

\begin{abstract}
The aim of this study was to explore the possibilities of using body condition score (BCS) or dairy character (DC) as indicators of mastitis and diseases other than mastitis in first-parity Danish Holsteins. The dataset included 28,948 observations on conformation scores and 365,136 disease observations. The analysis was performed using a multitrait linear sire model. Heritability estimates for BCS and DC were moderate $(0.25$ and 0.22 ), and heritability estimates for mastitis and diseases other than mastitis were low (0.038 and 0.022). Between BCS and diseases other than mastitis, the genetic correlation was -0.22 , whereas the genetic correlation was -0.16 between BCS and mastitis. The genetic correlation between $\mathrm{DC}$ and diseases other than mastitis was 0.43 , and between DC and mastitis it was 0.27 . The genetic correlation between BCS and DC was -0.61 . Residual correlations were close to 0 , except between BCS and DC (-0.37). Including DC as an indicator of diseases other than mastitis will increase the accuracy of the predicted breeding value for diseases, especially when the progeny group is small. Using BCS as an additional indicator of diseases did not increase the accuracy. Breeding for less DC will increase resistance to diseases.
\end{abstract}

(Key words: body condition score, dairy character, diseases, mastitis)

Abbreviation key: DC = dairy character, DOM100 = diseases other than mastitis recorded from -10 to 100 $\mathrm{d}$ from calving, MS50 $=$ mastitis recorded from -10 to

Received March 18, 2003.

Accepted July 2, 2003.

Corresponding author: J. Lassen; e-mail: jan.lassen@agrsci.dk.
$50 \mathrm{~d}$ from calving, $\mathbf{B C S} \leq \mathbf{1 0 0}=$ BCS scored before 100 DIM, BCS $>\mathbf{1 0 0}=$ BCS scored later than 100 DIM.

\section{INTRODUCTION}

The main focus in dairy cattle breeding has been on production traits. As the correlated response in energy intake is not large enough to cover the production potential (Van Arendonk et al., 1991), selection has lead to an increased negative energy balance in early lactation. This often leads to poorer reproductive performance, more mastitis, and more other diseases (Markusfeld et al., 1997; Broster and Broster, 1998). Therefore, cost for the farmer and discomfort for the cow increases with increased negative energy balance. To minimize this, indicators of energy balance could be included in the breeding program as a source of information. Body condition score is a subjective method of assessing the amount of metabolizable energy stored in fat and muscle (body reserves) of live animals (Ferguson et al., 1994). Dairy character (DC) is a type trait with a high negative correlation with BCS ( -0.47 to -0.77 ) (Veerkamp and Brotherstone, 1997) and is unfavorably correlated with disease resistance (0.41) (Hansen et al., 2002). For some time, BCS has been used as a management tool to estimate energy balance at specific periods of lactation in dairy cattle (Waltner et al., 1993; Markusfeld et al., 1997). Moreover, several studies suggests a phenotypic relationship between BCS and diseases (Gearhart et al., 1990; Domecq et al., 1997; Broster and Broster, 1998; Gillund et al., 2001), but these studies are based on small datasets collected in few herds. Recently, genetic studies have been made for BCS on data from different scoring systems (Jones et al., 1999; Pryce et al., 2000; Dechow et al., 2001; Koenen et al., 2001). Favorable genetic correlations between BCS and reproductive traits have been reported (Dechow et al., 2001; 
Table 1. Treatments considered in the disease traits. (Danish Cattle, 2002).

\begin{tabular}{ll}
\hline Overall trait & Treatments \\
\hline Reproductive diseases & $\begin{array}{c}\text { Abortion, endometritis, uterine prolapse, uterine torsion, endometritis treatment, follicular cysts, } \\
\text { retained placenta, caesarian section, vaginitis and other reproductive diseases. } \\
\text { Digestive diseases }\end{array}$ \\
$\begin{array}{c}\text { Diarrhoea, traumatic reticuloperitonitis, ludigestion, hypomagnesemia, ketosis, milk fever, } \\
\text { abomasal displacement, rumen acidosis, enteritis, bloat and other digestive and metabolic diseases. }\end{array}$ \\
$\begin{array}{c}\text { Heel erosion, interdigital dermatitis, claw trimming by vetenarian, interdigital necrobacillosis, interdigital } \\
\text { skin hyperplasia, laminitis, arthritis, sole ulcer, pressure injuries, tenosynovitis of hoofs and other leg injuries. }\end{array}$ \\
\hline
\end{tabular}

Pryce et al., 2002). A favorable genetic correlation between BCS and disease incidence is therefore plausible.

In Denmark, organized recording of DC and disease treatments has been practiced for several years, and BCS has been recorded since March 2001 (Danish Cattle, 2002). Earlier results on the current data showed that BCS could be considered the same trait during lactation (Lassen et al., 2003). The objective of this study was to estimate genetic parameters for BCS, DC, and disease incidence in Danish Holsteins. These parameters can clarify the value of using BCS and DC as indicators of diseases in a breeding program.

\section{MATERIALS AND METHODS}

\section{Data}

The data for this study originated from two datasets, both extracted from the Danish National Cattle Database. The first dataset contained observations for BCS and DC on first-parity Holstein cows. Body condition score and DC were scored by professional type classifiers as part of the national conformation scoring of cows in the period April 2001 to March 2002. The BCS classification was done using the method described by Ferguson et al. (1994). The scale used was from 1 to 9 with increments of 1 . Before editing, the dataset contained 30,625 observations from first parity. Cows classified earlier than $8 \mathrm{mo}$ from calving by a classifier with more than 500 observations are included. Age at calving had to be between 21 and 44 mo. The conformation dataset included 28,948 observations on BCS and DC. Of these 12,949 were scored earlier than 100 DIM $(\mathbf{B C S} \leq \mathbf{1 0 0})$ and 15,999 were scored later (BCS $>\mathbf{1 0 0})$.

The disease dataset was collected on first-parity cows calving in the period from January 1998 to June 2002. Most disease observations were recorded by a veterinarian. Mastitis was defined as all treatments related to the udder. Diseases other than mastitis were reproductive diseases, digestive diseases, and feet and leg diseases (Table 1). Both traits were binary. The original dataset included records from 486,734 animals. For both datasets, cows calving with an age in the range of 21 to 44 mo were included. Each year was split in two seasons. Herds with fewer than 10 observations in each season were discarded. To ensure that a herd conducted a reliable disease recording only herds with more than 0.3 treatments per calving for either mastitis or diseases other than mastitis were kept in the data (Pedersen et al., 2002). Only mastitis incidences recorded inside the range of -10 to $50 \mathrm{~d}$ after first calving (MS50) were considered, whereas treatments of diseases other than mastitis recorded inside the range of -10 to 100 $\mathrm{d}$ after first calving (DOM100) were considered. This is in accordance with the definition used in the Danish Breeding value estimation for resistance to mastitis and diseases other than mastitis described by Nielsen et al. (2000). The edited dataset contained 365,136 records on diseases from 21,845 herd-year-season groups.

The two datasets were merged, resulting in a dataset with observations on 369,926 cows, of which 24,199 had observations for all four traits. The number of observations for the different traits is shown in Table 2. The cows were sired by 6869 bulls. The pedigrees for these sires were traced as far back as possible using a siredam relationship, resulting in a total pedigree file with 27,420 animals.

\section{Methods}

The following multivariate sire-model was used to estimate the genetic parameters for the four traits:

$$
\mathbf{y}_{\mathrm{i}}=\mathbf{X}_{\mathbf{i}} \mathbf{b}_{\mathbf{i}}+\mathbf{Z}_{\mathbf{i}} \mathbf{s}_{\mathbf{i}}+e_{\mathbf{i}}, \mathbf{i}=1, \ldots, 4,
$$

Table 2. Number of observations, unadjusted means and standard deviations (SD) for BCS, BCS scored before 100 DIM (BCS $\leq 100)$, BCS scored later than 100 DIM (BCS > 100), dairy character (DC), diseases other than mastitis recorded from -10 to $100 \mathrm{~d}$ from calving (DOM100), and mastitis recorded from -10 to $50 \mathrm{~d}$ from calving (MS50).

\begin{tabular}{lcll}
\hline Trait & Observations & Mean & SD \\
\hline BCS & 28,948 & 4.26 & 0.96 \\
BCS $\leq 100$ & 12,949 & 4.14 & 0.94 \\
BCS $>100$ & 15,999 & 4.36 & 0.98 \\
DC & 28,948 & 5.41 & 0.81 \\
DOM100 & 365,136 & 0.18 & 0.39 \\
MS50 & 365,136 & 0.22 & 0.42 \\
\hline
\end{tabular}


where $\mathbf{y}_{1}, \mathbf{y}_{2}, \mathbf{y}_{3}$ and $\mathbf{y}_{4}$ are vectors containing observations on BCS, DC, diseases other than mastitis, and mastitis. $\mathbf{X}_{\mathbf{i}}$ was a design matrix relating the fixed effects in $\mathbf{b}_{\mathbf{i}}$ to the observations. $\mathbf{Z}_{\mathbf{i}}$ was a design matrix relating the random sire effects in $\mathbf{s}_{\mathbf{i}}$ to the observations and $\mathbf{e}_{\mathbf{i}}$ contained the residuals.

The fixed effects were herd-year-season (5984 and 21,845 levels for type traits and disease traits, respectively) and age in months at calving (24 levels) for all traits. In addition, for BCS and DC the fixed effects of classifier (5 levels) and the regression of DIM at classification was included. Assumptions of the random effects were:

$$
\operatorname{Var}\left(\begin{array}{l}
\mathbf{s} \\
\mathbf{e}
\end{array}\right) \sim N\left(\mathbf{0} ;\left[\begin{array}{cc}
\mathbf{G}_{\mathbf{0}} \otimes \mathbf{A} & \mathbf{0} \\
\mathbf{0} & \mathbf{r}_{\mathbf{0}} \otimes \mathbf{I}
\end{array}\right]\right)
$$

where $\mathbf{G}_{0}$ is a $4 \times 4$ matrix containing the (co)variance components of sires and $\mathbf{A}$ is the additive genetic relationship for the sires. $\mathbf{R}_{0}$ is a $4 \times 4$ matrix with the variance of the residuals in the diagonals and covariances in the off diagonals. I is an identity matrix of proper size according to the number of records.

The (co)variance components were estimated using the AI-REML-algorithm (Jensen et al., 1997) in the program DMU (Madsen and Jensen, 2000). Using a linear model for analysis of binary traits might underestimate the residual correlation between those traits; however, in a simulation study by Mäntysaari et al. (1991) a threshold model did not show any significant improvement in estimating parameters over a linear model.

To examine if there was a different genetic relationship between BCS and DOM100 when BCS was measured in different lactation periods, a trivariate model that included similar effects as for the four-trait model was applied estimating genetic parameters for $\mathrm{BCS} \leq 100, \mathrm{BCS}>100$, and DOM100.

\section{Accuracy of Index}

To quantify the value of DC and BCS as a source of information in an index for DOM100, a selection index was set up using the genetic parameters estimated in this study. The possible sources of information for the index were DOM100, BCS, and DC. The accuracy $\left(\mathrm{r}_{\mathrm{IA}}\right)$ was calculated for progeny group sizes $0,30,60$, and 120 , and it was assumed that the sire and maternal grandsire of the bull had progeny groups of 500 cows with recordings on the same traits as in the bulls progeny group. The calculations were conducted using SIP software (Wagenaar et al., 1995).

\section{RESULTS}

\section{Phenotypic Means}

Unadjusted means for the traits are shown in Table 2. Mean BCS was 4.26 for all observations. Body condition score mean was lower in early lactation (4.14) than in late lactation (4.36). Mean frequency of DOM100 and MS50 was 0.18 and 0.22 , respectively.

Forty-four percent of the disease records in DOM100 were retained placenta, endometritis, or abortion and $18 \%$ were heel erosion or pressure injuries on legs. Only $2 \%$ of the treatments were ketosis, milk fever, rumen acidosis, and abomasal displacement. The rest of the diseases presented in Table 1 contributed $36 \%$ of the diseases.

\section{Genetic Parameters}

The estimated heritability for BCS and DC were moderate $(0.25$ and 0.22 , respectively), whereas the heritability estimates for DOM100 and MS50 were low (0.022 and 0.038 , respectively) (Table 3 ).

All genetic correlations were moderate to low (Table 4). The genetic correlation was stronger between DC and DOM100 (0.44) than between BCS and DOM100 $(-0.21)$. Mastitis had low genetic correlation with BCS and DC ( -0.15 and 0.22$)$. The highest absolute genetic correlation was between BCS and DC $(-0.61)$. The residual correlation between BCS and DC of -0.37 implied that cows that score high for BCS due to environmental reasons scored low for DC. The other residual correlations were close to 0 .

Analyzing BCS before and after 100 DIM as two different traits gave heritability estimates of 0.27 and

Table 3. Estimated sire variances $\left(\sigma_{\mathrm{s}}^{2}\right)$, residual variances $\left(\sigma_{\mathrm{e}}^{2}\right)$ and heritabilities $\left(\mathrm{h}^{2}\right)$ with standard errors in parentheses for BCS, dairy character (DC), diseases other than mastitis recorded from -10 to $100 \mathrm{~d}$ from calving (DOM100), and mastitis recorded from -10 to $50 \mathrm{~d}$ from calving (MS50).

\begin{tabular}{llll}
\hline Trait & $\sigma_{\mathrm{s}}^{2}$ & $\sigma_{\mathrm{e}}^{2}$ & $\mathrm{~h}^{2}$ \\
\hline BCS & $0.041(0.005)$ & $0.63(0.006)$ & $0.25(0.027)$ \\
DC & $0.032(0.004)$ & $0.54(0.005)$ & $0.22(0.025)$ \\
DOM100 & $0.00078(0.00009)$ & $0.14(0.0003)$ & $0.022(0.0036)$ \\
MS50 & $0.0015(0.0006)$ & $0.16(0.0004)$ & $0.038(0.0041)$ \\
\hline
\end{tabular}


Table 4. Estimated genetic correlations (below diagonal) and residual correlations (above diagonal) with standard errors in parentheses for BCS, dairy character (DC), diseases other than mastitis recorded from -10 to $100 \mathrm{~d}$ from calving (DOM100), and mastitis recorded from -10 to $50 \mathrm{~d}$ from calving (MS50).

\begin{tabular}{llccc}
\hline Trait & BCS & DC & DOM100 & MS50 \\
\hline BCS & & $-0.37(0.01)$ & $-0.04(0.002)$ & $0.007(0.007)$ \\
DC & $-0.61(0.06)$ & & $0.03(0.007)$ & $0.009(0.007)$ \\
DOM100 & $-0.22(0.10)$ & $0.43(0.09)$ & & $0.011(0.007)$ \\
MS50 & $-0.16(0.09)$ & $0.27(0.09)$ & $0.32(0.07)$ & \\
\hline
\end{tabular}

0.24 , respectively (Table 5). The genetic correlation between $\mathrm{BCS}<100$ and $\mathrm{BCS}>100$ was 0.95 . The heritability estimate for DOM100 was 0.022 , which is identical to the results from the four-variate model. The BCS $>100$ tended to have a somewhat higher absolute genetic correlation with DOM100 (-0.30) than $\mathrm{BCS} \leq 100(-0.13)$.

\section{Accuracy of Index}

Correlations $\left(\mathrm{r}_{\mathrm{IA}}\right)$ between the true breeding value and an index with different information sources were calculated for resistance to diseases other than mastitis (Table 6).

Using BCS as the only indicator of diseases (scenario 1) gave the lowest $r_{I A}(<0.20)$. If no daughters had observations on diseases, $\mathrm{r}_{\mathrm{IA}}$ was never higher than 0.42 (scenario 1 to 3 ). When observations on diseases were included in the index, $\mathrm{r}_{\mathrm{IA}}$ was never lower than 0.48 (scenario 4 to 7). With all information sources available and 120 daughters in the progeny group the $\mathrm{r}_{\mathrm{IA}}$ was 0.74 (scenario 7). Leaving out BCS did not decrease the $\mathrm{r}_{\text {IA }}$ when 120 daughters were available.

Including information on diseases and DC increased $\mathrm{r}_{\mathrm{IA}}$ compared with only including information on disease (scenario 4 and 6). Including information on BCS did not increase $\mathrm{r}_{\mathrm{IA}}$ when daughters were already scored for DC. With larger progeny group, the value of DC as an indicator of diseases decreased. When no daughter observations for DOM100 were available and DC and BCS were available, including pedigree information on $\mathrm{BCS}$ and DC did not increase $\mathrm{r}_{\mathrm{IA}}$ when pedigree information for DOM100 was available (scenario 4-7).

\section{DISCUSSION}

\section{Heritability}

The estimates of the heritability for BCS was $0.25 \pm$ 0.027. This is similar to results from The Netherlands (Koenen et al., 2001), UK (Jones et al., 1999), and US (Dechow et al., 2001). The estimates of the heritability of DC was $0.22 \pm 0.025$, which is similar to other studies (Brotherstone, 1994; Weigel et al., 1997; Sørensen et al., 2000). The estimates of the heritabilities of DOM100 and MS50 are low (0.022 and 0.038), but similar to earlier studies in Denmark (Nielsen et al., 1999; Hansen et al., 2002). As in this study, earlier studies used linear sire models to analyze binary traits.

\section{Genetic Correlations}

There was a negative genetic correlation between BCS and DOM100 (-0.22 \pm 0.10$)$, which indicated that cows with high genetic merit for BCS are genetically less disposed to diseases, and the same was the case for mastitis $(-0.16 \pm 0.09)$. Dairy character is unfavorably genetically correlated to disease incidence $(0.43 \pm 0.09)$. This is in agreement with results presented by Hansen et al. (2002), who found a genetic correlation between DC and disease incidence of 0.41 .

Both DC and BCS are indicators of energy balance (Veerkamp and Brotherstone, 1997). An increased negative energy balance is associated with more diseases (Collard et al., 2000). Therefore, an increase in diseases incidences is expected, when selecting for a higher DC and a lower BCS. There is a relationship between DC and BCS. Dairy character is not well-defined inter-

Table 5. Genetic correlations (below diagonal), residual correlations (above diagonal) and heritabilities (diagonal) with standard errors for BCS scored before 100 DIM (BCS $\leq 100$ ), BCS scored later than 100 DIM (BCS > 100), and diseases other than mastitis recorded from -10 to $100 \mathrm{~d}$ from calving (DOM100).

\begin{tabular}{lccc}
\hline Trait & BCS $\leq 100$ & BCS $>100$ & DOM100 \\
\hline BCS $\leq 100$ & $\mathbf{0 . 2 7}(0.039)$ & $0^{1}$ & $-0.051(0.011)$ \\
BCS $>100$ & $0.95(0.06)$ & $\mathbf{0 . 2 4}(0.033)$ & $-0.046(0.0098)$ \\
DOM100 & $-0.13(0.12)$ & $-0.30(0.10)$ & $\mathbf{0 . 0 2 2}(0.0036)$ \\
\hline
\end{tabular}

${ }^{1}$ Assumed to be zero because the traits were measured on different animals. 
Table 6. Correlation between the true breeding value and index $\left(\mathrm{r}_{\mathrm{IA}}\right)$ for diseases other than mastitis recorded from -10 to $100 \mathrm{~d}$ from calving with different information on diseases, DC and BCS.

\begin{tabular}{|c|c|c|c|c|c|c|c|}
\hline \multirow[b]{2}{*}{ Trait } & \multicolumn{7}{|c|}{ Observations in each scenario $^{1}$} \\
\hline & 1 & 2 & 3 & 4 & 5 & 6 & 7 \\
\hline Observation on diseases & & & & $\mathrm{x}$ & $\mathrm{x}$ & $\mathrm{x}$ & $\mathrm{x}$ \\
\hline Classification on DC & & $\mathrm{x}$ & $\mathrm{x}$ & & & $\mathrm{x}$ & $\mathrm{x}$ \\
\hline Classification on BCS & $\mathrm{x}$ & & $\mathrm{x}$ & & $\mathrm{x}$ & & $\mathrm{x}$ \\
\hline $\mathrm{r}_{\mathrm{IA}} 0$ daughters & 0.12 & 0.24 & 0.24 & 0.48 & 0.48 & 0.48 & 0.48 \\
\hline $\mathrm{r}_{\mathrm{IA}} 30$ daughters & 0.18 & 0.36 & 0.37 & 0.56 & 0.57 & 0.61 & 0.61 \\
\hline $\mathrm{r}_{\mathrm{IA}} 60$ daughters & 0.19 & 0.39 & 0.39 & 0.62 & 0.63 & 0.67 & 0.67 \\
\hline $\mathrm{r}_{\mathrm{IA}} 120$ daughters & 0.20 & 0.41 & 0.42 & 0.70 & 0.71 & 0.74 & 0.74 \\
\hline
\end{tabular}

${ }^{1}$ In each scenario sires and grand sires were assumed to have 500 daughters with observations for the same traits used in the index.

nationally. In Denmark, DC is defined as a measure of the dimensions of the skeleton. This is not the case in other countries where flesh covering also is a part of the definition of the trait. Body condition score is a visual assessment of body tissue (Ferguson et al., 1994) and can be used to interpret the physiological status of the cow at a given time of lactation. However, both traits are subjectively scored, and it is likely that DC also is related to muscle and fat covering on the back and the ribs of the cow. The physiological interpretation of BCS makes the biological understanding of the genetic relationship between DC, BCS, and DOM100 in this study difficult. In the present data very few observations of BCS and DC were registered before $30 \mathrm{~d}$ after calving, and none are from the dry period. In this period, BCS changes are more extreme than after $30 \mathrm{~d}$ from calving (Koenen et al., 2001). Dairy character also changes in early lactation but not as extreme as BCS. The low number of observations in early lactation could be the reason why $\mathrm{DC}$ is more highly correlated to DOM100 than BCS in the present study. There tended to be a stronger genetic correlation between DOM100 and BCS measured in late lactation compared with BCS measured in early lactation, though not significant. This difference could be due to sampling error, or a nonlinear genetic relationship between BCS and DOM100 within $100 \mathrm{~d}$ from calving may exist. Phenotypically very fat or very thin cows have increased risk of diseases in this period. Plotting breeding values for DOM100 against BCS did not support a nonlinear relationship. Very few observations were made on BCS and DC in early lactation, however.

Strong genetic associations between BCS and reproduction traits such as first-service conception rate and days from calving to first service have been found (Pryce et al., 2000; Dechow et al., 2001; Veerkamp et al., 2001). In these analyses, there was one observation per cow, and the observations were made during all stages of the lactation but concentrated in midlactation. The reproductive traits were measured in a later stage of lac- tation than the disease traits in the current dataset, and in a stage of lactation where more observations for BCS were available. Therefore, comparing this type of data for BCS with reproduction traits gave stronger genetic correlations than comparing them to disease traits measured in early lactation.

A second reason for the relatively low genetic correlation between BCS and DOM100 could be that the frequency of digestive diseases was low in first-parity cows compared with reproductive diseases and feet and leg diseases. Therefore, analysis of later-parity cows with a higher frequency of digestive diseases would be interesting. It would be of interest to investigate if BCS measured in first lactation is a better indicator of diseases in second lactation than in first lactation.

Hansen et al. (2002) found a genetic correlation of 0.39 between dairy character and diseases other than mastitis measured between $d-10$ to 100 from calving after adjustment for protein yield. When not adjusting for protein yield, this correlation was 0.41 . When comparing data on type traits in US Holsteins and other data on disease records in first-parity Danish Holsteins an approximate genetic correlation between dairy form and frequency of all diseases other than mastitis were estimated to 0.73 (Rogers et al., 1999). After adjusting for PTA for milk yield this correlation was 0.53 . Pryce et al. (2002) found a genetic correlation between BCS and calving interval of -0.48 before adjustment for phenotypic level of milk yield and -0.22 after. Therefore, production plays a role in the interpretation of these genetic and phenotypic relationships. A high level of production aggravates the unfavorable relation among BCS, DC, and DOM100. Even after adjustment for milk yield, conformation traits like BCS and DC provide information on the genetic potential of fitness traits like disease resistance.

\section{Accuracy of Index}

The accuracy of an index for a trait using different sources of information is a way to illustrate the effect 
of the genetic relationship between traits. Accuracy for the index on diseases above 0.42 could not be achieved without direct information on disease performance from daughters. Selection for disease resistance without observations for diseases is not likely to be effective. When direct information on diseases was included and progeny group sizes are large the effect of including DC as an indicator was small. Using BCS as an indicator of diseases when DC observations are available will add little information. When estimating the genetic correlation between DC and OD100 conditional on BCS and the genetic correlation between BCS and OD100 conditional on DC, the correlations were 0.39 and 0.06 , respectively. So most of the information achieved from BCS is already available in DC.

In Denmark, DC is already used as an indicator in the calculation of breeding value for mastitis to increase the accuracy of the index (Pedersen et al., 2002). However, DC is also included in the calculation of the breeding value for type and more emphasis has been put on dairy character to improve type compared to resistance to mastitis, especially when selecting dams for bulls.

\section{CONCLUSIONS}

When DC and BCS are recorded as in the present Danish conformation scoring system, observations on DC will add more information as a genetic indicator of disease resistance than BCS. Instead of selecting for a higher DC scores, selection for lower DC should be practiced to achieve improved disease resistance.

\section{REFERENCES}

Danish Cattle. 2002. Principles of Danish cattle breeding. Online. Available: http://www.lr.dk/kvaeg/diverse/principles.pdf.

Broster, W. H., and V. J. Broster. 1998. Body score of dairy cows. J. Dairy Res. 65:155-173.

Brotherstone, S. 1994. Genetic and phenotypic correlations between linear type traits and production traits in Holstein-Friesian cattle. Anim. Prod. 59:183-187.

Collard, B. L., P. J. Boettcher, J. C. M. Dekkers, D. Petitclerc, and L. R. Schaeffer. 2000. Relationship between energy balance and health traits of dairy cattle in early lactation. J. Dairy Sci. 83:2683-2690.

Dechow, C. D., G. W. Rogers, and J. S. Clay. 2001. Heritabilities and correlations among body condition scores, production traits, and reproductive performance. J. Dairy Sci. 84:266-275.

Domecq, J. J., A. L. Skidmore, J. W. Lloyd, and J. B. Kaneene. 1997. Relationship between body condition scores and conception at first artificial insemination in a large dairy herd of high yielding Holstein cows. J. Dairy Sci. 80:113-120.

Ferguson, J. D., D. T. Galligan, and N. Thomsen. 1994. Principal descriptors of body condition score in Holstein cows. J. Dairy Sci. 77:2695-2703.

Gearhart, M. A., C. R. Curtis, H. N. Erb, R. D. Smith, C. J. Sniffen, L. E. Chase, and M. D. Cooper. 1990. Relationship of changes in condition score to cow health in Holsteins. J. Dairy Sci. 73:3132-3140.
Gillund, P., O. Reksen, Y. T. Gröhn, and K. Karlberg. 2001. Body condition related to ketosis and reproductive performance in Norwegian dairy cows. J. Dairy Sci. 84:1390-1396.

Hansen, M., M. S. Lund, M. K. Sørensen, and L. G. Christensen. 2002. Genetic parameters of dairy character, protein yield, clinical mastitis, and other diseases in the Danish Holstein cattle. J. Dairy Sci. 85:445-452.

Jensen, J., E. A. Mäntysaari, P. Madsen, and R. Thompson. 1997. Residual maximum likelihood estimation of (co)variance components in multivariate mixed linear models using average information. J. Ind. Soc. Agric. Stat. 49:215-236.

Jones, H. E., I. M. S. White, and S. Brotherstone. 1999. Genetic evaluation of Holstein Friesian sires for daugther condition-score changes using a random regression model. Anim. Sci. 68:467-475.

Koenen, E. P. C., R. F. Veerkamp, P. Dobbelaar, and G. De Jong. 2001. Genetic analysis of body condition score of lactating Dutch Holstein and Red-and-White heifers. J. Dairy Sci. 84:1265-1270.

Lassen, J., M. Hansen, M. K. Sørensen, G. P. Aamand, L. G. Christensen, and P. Madsen. 2003. Genetic analysis of body condition score in first parity Danish Holstein cows. J. Dairy Sci. (accepted)

Madsen, P., and J. Jensen. 2000. DMU: A user's guide. A package for analysing multivariate mixed models. Version 6, release 4., DJF, Foulum, Denmark.

Markusfeld, O., N. Galon, and E. Ezra. 1997. Body condition score, health, yield and fertility in dairy cows. Vet. Rec. 141:67-72.

Mäntysaari, E. A., R. L. Quaas, and Y. T. Gröhn. 1991. Simulation study on covariance component estimation for two binary traits in an underlying continuous scale. J. Dairy Sci. 74:580-591.

Nielsen, U. S., G. A. Pedersen, J. Pedersen, and J. Jensen. 1999. Genetic variation in disease traits and their relationships with survival in Danish dairy cattle. Interbull Bull. 21:170-177. Uppsala, Sweden.

Nielsen, U. S., G. P. Aamand, and T. Mark. 2000. National genetic evaluation of udder health and other health traits in Denmark. Interbull Bull. no. 25:143-151. Bled, Slovenia.

Pedersen, G. A., M. B. Almskou, A. Fogh, U. S. Nielsen, J. H. Jakobsen, J. Pedersen, and O. M. Pedersen. 2002. Arsstatistik-Avl 2001-2002, Landskontoret for Kvæg, Skejby.

Pryce, J. E., M. P. Coffey, and S. Brotherstone. 2000. The genetic relationship between calving interval, body condition score and linear type and management traits in registered Holsteins. J. Dairy Sci. 83:2664-2671.

Pryce, J. E., M. P. Coffey, S. Brotherstone, and J. A. Wooliams. 2002. Genetic relationships between calving interval and body condition score conditional on milk yield. J. Dairy Sci. 85:1590-1595.

Rogers, G. W., G. Banos, and U. Sander-Nielsen. 1999. Genetic correlations among protien yield, productive life, and type traits from the United States and diseases other than mastitis from Denmark and Sweden. J. Dairy Sci. 82:1331-1338.

Sørensen, M. K., J. Jensen, and L. G. Christensen. 2000. Udder conformation and mastitis resistance in Danish first-lactation cows: Heritabilities, genetic and environmental correlations. Acta Agric. Scand. Sect. A. Anim. Sci. 50:72-82.

Van Arendonk, J. A. M., G. J. Nieuwhof, H. Vos, and S. Korver. 1991. Genetic aspects of feed intake and efficiency in lactating dairy heifers. Livest. Prod. Sci. 29:263-275.

Veerkamp, R. F., and S. Brotherstone. 1997. Genetic correlations between linear type traits, food intake, live weight and condition score in Holstein Friesian dairy cattle. J. Anim. Sci. 64:385-392.

Veerkamp, R. F., E. P. C. Koenen, and G. De Jong. 2001. Genetic correlations among body condition score, yield and fertility in first-parity cows estimated by random regression models. J. Dairy Sci. 84:2327-2335.

Wagenaar, D., J. A. M. Van Arendonk, and M. Kramer. 1995. Selection Index Program (SIP). Wageningen Agricultural University. The Netherlands. Online. Available: http://www.zod.wau.nl/abg/.

Waltner, S. S., J. P. McNamara, and J. K. Hillers. 1993. Relationships of body condition score to production variables in high producing Holstein dairy cattle. J. Dairy Sci. 76:3410-3419.

Weigel, D. J., B. G. Cassell, and R. E. Pearson. 1997. Prediction of transmitting abilities for productive life and lifetime profitability from production, somatic cell count, and type traits in milk markets for fluid milk and cheese. J. Dairy Sci. 80:1398-1405. 